\title{
Predictors of the Progression of Dementia Severity in Brazilian Patients with Alzheimer's Disease and Vascular Dementia
}

\author{
Márcia L. Chaves, ${ }^{1}$ Ana L. Camozzato, ${ }^{2}$ Cristiano Köhler, ${ }^{1}$ and Jeffrey Kaye ${ }^{3}$ \\ ${ }^{1}$ Dementia Outpatient Clinic and Behavioral Sciences Program, Neurology Service and Medical Sciences Post-Graduation Course, \\ Hospital de Clínicas de Porto Alegre, Universidade Federal do Rio Grande do Sul School of Medicine, Porto Alegre 90035-903, Brazil \\ ${ }^{2}$ Dementia Outpatient Clinic and Behavioral Sciences Program, Neurology Service, Hospital de Clínicas de Porto Alegre, \\ Universidade Federal do Rio Grande do Sul School of Medicine, Porto Alegre 90035-903, Brazil \\ ${ }^{3}$ Layton Aging and Alzheimer's Disease Center, Oregon Health \& Science University, Portland, OR 97239, USA
}

Correspondence should be addressed to Márcia L. Chaves, mchaves@hcpa.ufrgs.br

Received 13 September 2009; Revised 15 December 2009; Accepted 17 January 2010

Academic Editor: Leonardo Pantoni

Copyright (C) 2010 Márcia L. Chaves et al. This is an open access article distributed under the Creative Commons Attribution License, which permits unrestricted use, distribution, and reproduction in any medium, provided the original work is properly cited.

\begin{abstract}
Introduction. This study evaluates the progression of dementia and identifies prognostic risk factors for dementia. Methods. A group of 80 Brazilian community residents with dementia (34 with Alzheimer's disease and 46 with vascular dementia) was assessed over the course of 2 years. Data were analyzed with Cox regression survival analysis. Results. The data showed that education predicted cognitive decline $(\mathrm{HR}=1.2 ; P<.05)$ when analyzed without controlling for vascular risk factors. After the inclusion of vascular risk factors, education $(\mathrm{HR}=1.32 ; P<.05)$ and hypertension were predictive for cognitive decline $(\mathrm{HR}=38 ; P<.05)$, and Alzheimer's disease diagnosis was borderline predictive $(P=.055)$. Conclusion. Vascular risk factors interacted with the diagnosis of vascular dementia. Education was a strong predictor of decline.
\end{abstract}

\section{Introduction}

It is estimated that 24.3 million people suffer from dementia today, with 4.6 million new cases every year. Of those with dementia, $60 \%$ live in developing countries, and the rate of increase in prevalence is predicted to be three to four times higher in developing countries than in developed countries [1].

In most prevalence studies, Alzheimer's disease (AD) has been associated with $70 \%$ or more of all cases of dementia and the main contributor to the steep increase with age in the prevalence of dementia [2]. In turn, dementia with a vascular component comprises nearly half of all cases of dementia in persons aged 85 years and older [3]. Patients with vascular dementia $(\mathrm{VaD})$ have poorer survival than those with $\mathrm{AD}$ : the median survival from dementia onset to death is 3.9 years for patients with vascular dementia $(\mathrm{VaD})$ and 7.1 years for patients with $\mathrm{AD}[4]$.
It is important to evaluate the progression of dementia and to estimate predictors of cognitive and functional decline in patients with an established diagnosis of dementia. Gender, education, and time from $\mathrm{AD}$ onset did not significantly predict cognitive and functional decline in one study [5]. In another study, there were also no predictors of disease progression except for gender: men exhibited a greater rate of cognitive decline than women [6]. Another report demonstrated that, during the early and very late stages of $\mathrm{AD}$, cognitive deterioration was slower than during the middle stages and no clinical variables other than the degree of cognitive impairment and previous rate of cognitive decline predicted deterioration [7].

Higher education and participation in prediagnostic activities have been associated with faster cognitive decline in many AD longitudinal studies [8-10]. In addition, psychotic symptoms and disruptive behavior predicted faster disease progression in both the cognitive and functional dimensions 
of $\mathrm{AD}$ [11]. Diffuse cognitive impairments predicted cognitive decline, and visuospatial deficits predicted functional progression in $\mathrm{AD}$ [12].

Among patients with $\mathrm{VaD}$, longitudinal changes in instrumental and basic activities of daily living were most strongly associated with changes in executive functioning and memory abilities, respectively [13]. Independent of both level and rate of change of prestroke cognitive performance and other risk factors for cognitive decline, incident stroke was associated with more than twice the risk of subsequent dementia (hazard ratio, 2.1; 95\% CI, 1.55 to 2.81). Among those persons who developed dementia after stroke, 58.2\% were diagnosed with $\mathrm{VaD}$, and $32.7 \%$ were diagnosed with $\mathrm{AD}$ [14]. High cerebrovascular disease burden in $\mathrm{VaD}$ was associated with the worst survival rate [15].

$\mathrm{VaD}$ and $\mathrm{AD}$ have been linked to a number of cardiovascular factors [16-20], but the effect of vascular risk factors on the progression of already-established dementia has been less studied. Vascular risk factors measured clinically and biochemically did not significantly increase the rate of deterioration during 18 months in $\mathrm{AD}$ patients with a low burden of cerebrovascular risk factors; however, cerebrovascular events predicted cognitive decline in AD [21]. Decreased cardiovascular reactivity, atrial fibrillation, systolic hypertension, and angina also predicted faster decline in $\mathrm{AD}$ patients $[22,23]$. History of coronary artery bypass graft surgery, diabetes, and treatment with antihypertensive medications were associated with slower rate of decline [23]. On the other hand, a longitudinal study did not find an association between baseline cardiovascular risk factors and progression from CDR 1.0 to CDR 2.0 over an 18-month follow-up [24].

We hypothesized that $\mathrm{VaD}$ patients would present faster decline than $\mathrm{AD}$ patients. We also hypothesized that younger and more educated patients and those with higher exposure to vascular risk factors would present faster decline. As $\mathrm{VaD}$ patients presented with more vascular risk factors, we supposed that this combination would also increase the rate of progression of $\mathrm{VaD}$.

The main objective of the present study was the evaluation of the progression of dementia (the severity of decline) in $\mathrm{AD}$ and $\mathrm{VaD}$. Most patients were mildly to moderately demented at baseline. We also analyzed predictors of progression of severity of dementia.

\section{Methods}

Eighty $\mathrm{AD}$ and $\mathrm{VaD}$ patients were selected consecutively from the Dementia Outpatient Clinic and enrolled in a cohort study to evaluate the progression of dementia severity and clinical predictors of decline. This sample size was sufficient to detect $15 \%$ differences in risk for decline $(P<.05)$. The diagnosis of $\mathrm{AD}$ followed the criteria of the NINCDS-ADRDA for probable AD. VaD was diagnosed by the National Institute of Neurological Disorders and Stroke-Association Internationale pour la Recherche et l'Enseignement en Neurosciences (NINDS-AIREN) criteria [25]. The Hachinski Ischemic Score (HIS) [26] was also applied in all patients to verify that an ischemic process was associated with $\mathrm{VaD}$ and to exclude ischemia in $\mathrm{AD}$.
The assessments were carried out every 6 months over 2 years. At the interviews, patients, corroborated by their caregivers, were evaluated for cognition and behavior. The following assessments were made at baseline. Demographic data, including educational attainment and Portuguese fluency, were collected for all patients. The risk factors for cerebrovascular disease, hypertension, and diabetes were evaluated by clinical history and physical examination. Hypertension was defined as systolic blood pressure of $\geq 140 \mathrm{mmHg}$, diastolic blood pressure of $\geq 90 \mathrm{mmHg}$, or by the use of prescribed antihypertensive medication. Diabetes mellitus was considered present if the patient had a fasting glucose level of $\geq 120 \mathrm{mg} / \mathrm{dL}$ or used antidiabetic medication. Family history of dementia and neuroimaging findings were also collected at study entry, and a neurological examination was performed. A senior neuroradiologist, working with dementia neuroimage for more than 5 years, blinded to the clinical data, performed the readings of CT scans. The analyses were qualitative. Atrophy was defined subjectively, based on telencephalic cortical sulci prominence and lateral ventricles diameter. Leukoaraiosis was defined as bilateral and nearly symmetrical areas of decreased density of the periventricular white matter and centrum semiovale. Focal abnormality was described as areas of hypodensity without leukoaraiosis, expressing ischemic lacunae, on neuroimage.

Baseline severity of dementia was assessed with the Clinical Dementia Rating (CDR) scale, applied by trained interviewers $[27,28]$. The CDR was considered a categorical variable by coding mild, moderate and severe as 1,2 , and 3 , respectively.

The detailed examinations at each follow-up assessment included medical, neurological, neuropsychiatric, and cognitive evaluations, by three neurologists and one psychiatrist. The CDR scale was also used at each follow-up assessment.

The main outcome assessed was the disease progression in terms of dementia severity. The change from a milder category on CDR to a severer condition on this scale (i.e., a one-point drop in CDR) was considered an indicator of the progression of dementia severity. The study was approved by the Ethics Committee for Medical Research at the University Hospital where it took place. Informed consent was obtained from the subjects or their nearest relatives or both.

\section{Statistical Analyses}

Progression of dementia severity was evaluated by Cox regression survival analysis, and survival curves were derived with the Kaplan-Meier's method. The date of the follow-up when a one-point drop in CDR was recorded marked the occurrence of disease progression. The following variables were considered as predictors of disease progression: age, sex, education, diagnosis ( $\mathrm{AD}$ or $\mathrm{VaD})$, diabetes, hypertension, and neuroimaging findings at study entry. Two Cox proportional hazards models were performed to determine whether baseline variables could predict the progression of dementia. In the first model, age, sex, educational level, family history of dementia, neuroimaging findings, and diagnosis $(\mathrm{AD}$ or $\mathrm{VaD})$ were considered as explanatory variables. 
In the second analysis, vascular risk factors were added as an explanatory variable to the previously used factors in the model.

All procedures were carried out with the Statistical Package for the Social Sciences (SPSS) 14 for Windows.

\section{Results}

The sample of the first evaluation (at entry to the study) was composed of 80 patients: 39 (49\%) males and 41 (51\%) females. The mean \pm SD age at entry to the study was $69.9 \pm$ 8.9 years (range: 50 to 87 years), and education level varied from 0 to 16 years of schooling $(4.57 \pm 4.02$, mean $\pm \mathrm{SD})$. Of the 80 patients in our first analysis, $34(43 \%)$ fulfilled criteria for probable $\mathrm{AD}$, and 46 (57\%) for probable VaD. All patients with $\mathrm{VaD}$ had a history of the previous stroke at baseline. Of the 80 patients enrolled in the study, 28 did not present any vascular risk factor. Hypertension was observed in 37 patients, diabetes in 6 , and the association of hypertension and diabetes in 9. $\mathrm{AD}$ patients at baseline were mild (CDR $=$ 1) $(n=20)$, moderate $(\mathrm{CDR}=2)(n=9)$, and severe $(\mathrm{CDR}=3)(n=5)$, and VaD patients were mild $(\mathrm{CDR}=1)$ $(n=27)$ and moderate $(\mathrm{CDR}=2)(n=19)$. The sample included only community-dwelling patients (Table 1).

Progression of dementia severity during the 2-year follow-up was observed in 17 patients. No improvements were observed during the follow-up. Stroke occurrence in AD patients or reoccurrence in $\mathrm{VaD}$ patients was not observed during the 2-year follow-up.

In the first multivariate Cox model without vascular risk factors, education was the only significant variable $(\mathrm{HR}=1.2$; CI 95\% 1.02-1.37; $P=.024)$. One more year of education increased the risk (hazard ratio) 1-2-fold (Table 2).

However, in the second multivariate Cox model with the inclusion of vascular risk factors (hypertension, diabetes, and hypertension + diabetes), education and hypertension were significant factors. Diagnosis $(\mathrm{AD}$ or $\mathrm{VaD})$ was not significant in the first model $(P=.94)$, but showed a borderline effect in the second model $(P=.055)$. For the second model, one year more of education increased the risk of dementia progression 1.32 times, and the presence of hypertension increased the risk 38 times (Table 3 ).

Figures 1 and 2 display the rate of progression of $\mathrm{AD}$ and $\mathrm{VaD}$ obtained from the two Cox regression models. In Figure 1, the progression was similar between $\mathrm{AD}$ and $\mathrm{VaD}$. On the other hand, Figure 2 demonstrates slow progression of $\mathrm{VaD}$-almost $4 / 5$ of the period of observation with acceleration at the end of the period — and fast progression of $\mathrm{AD}$.

\section{Discussion}

This longitudinal study was designed to evaluate the rate of progression and predictors of progression of dementia severity. The main findings of the present study were the similar evolution of severity in both $\mathrm{AD}$ and $\mathrm{VaD}$, and the impact of hypertension on the progression of dementia. When the course of $\mathrm{VaD}$ was analyzed without control for the vascular

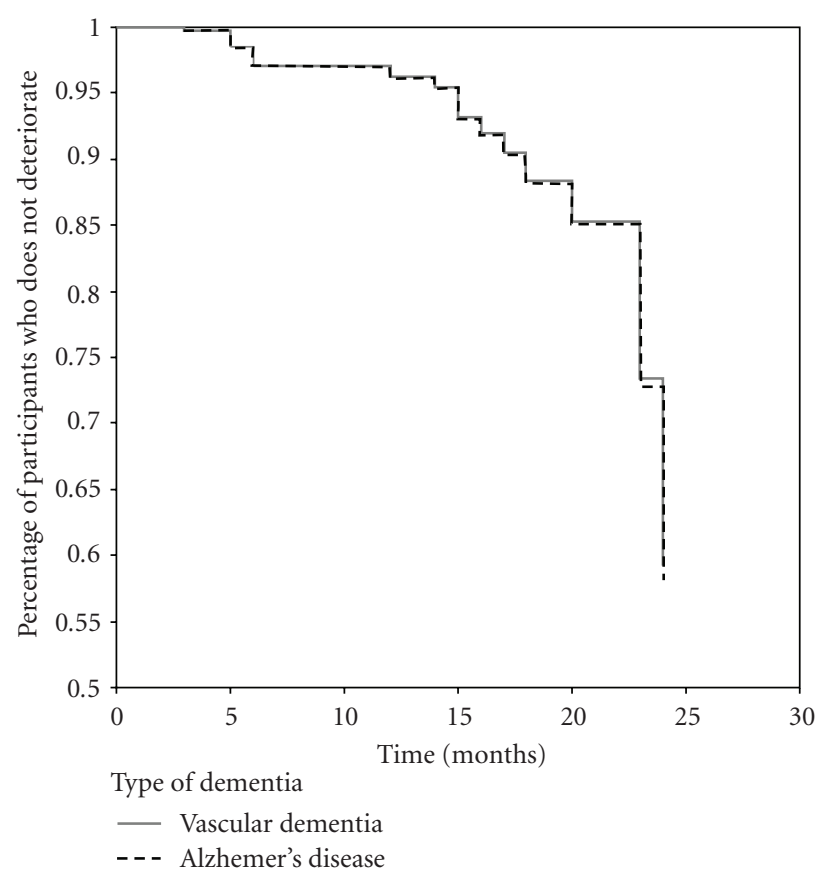

FIgURE 1: Survival Rate in Relation to Severity of Dementia (CDR scale): without vascular risk factor in the model.

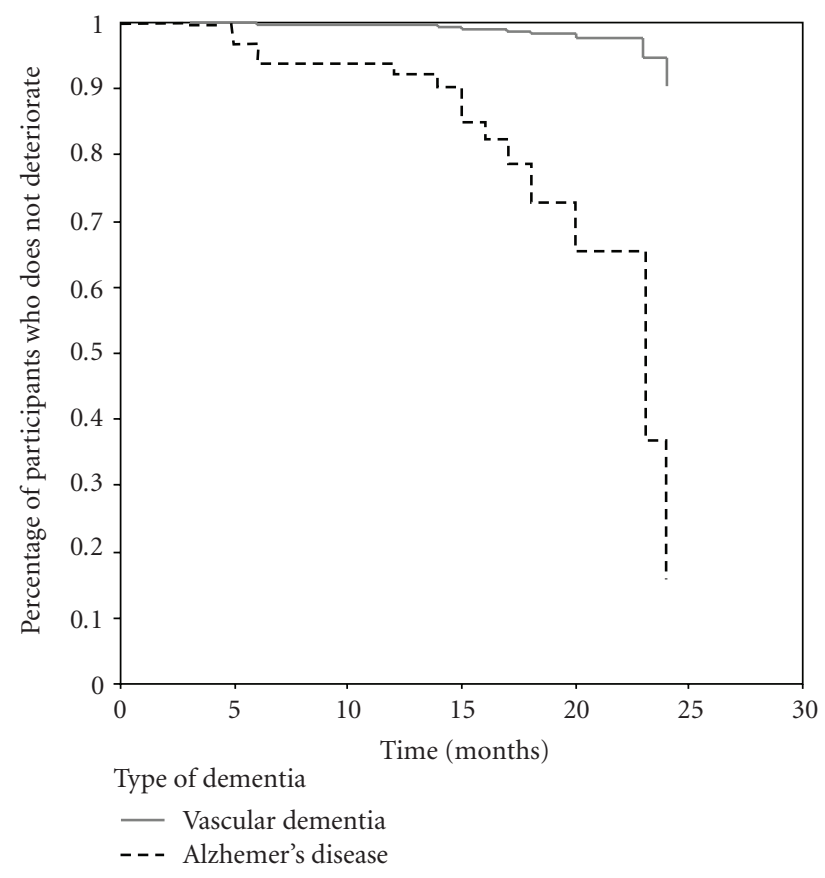

Figure 2: Survival Rate in Relation to Severity of Dementia (CDR scale): with vascular risk factor in the model.

risk factors, the progression was similar to that of AD. After the addition of these factors-specifically hypertensionto the model, $\mathrm{VaD}$ presented slower progression $(P=$ $.055)$. Additionally, higher education was associated with faster disease progression in dementia patients in both mathematical models. 
TABle 1: Demographic and clinical data at study entry.

\begin{tabular}{|c|c|c|}
\hline Variable & Alzheimer $(N=34)$ & $\operatorname{Vascular}(N=46)$ \\
\hline Age (in years) mean $\pm \mathrm{SD}$ (range) & $73.23 \pm 7.72(60-87)$ & $67.41 \pm 9.08(50-86)$ \\
\hline \multicolumn{3}{|l|}{ Sex } \\
\hline Male & $11(32 \%)$ & $28(61 \%)$ \\
\hline Female & $23(68 \%)$ & $18(39 \%)$ \\
\hline Educational Attainment (in years) mean \pm SD (range) & $4.30 \pm 3.99(0-16)$ & $4.76 \pm 4.06(0-16)$ \\
\hline \multicolumn{3}{|l|}{ Vascular risk factors } \\
\hline None & $28(82 \%)$ & - \\
\hline Hypertension & $04(12 \%)$ & $33(72 \%)$ \\
\hline $\mathrm{DM}$ & $02(6 \%)$ & $04(9 \%)$ \\
\hline Hypertension + DM & $00(0 \%)$ & $09(20 \%)$ \\
\hline \multicolumn{3}{|l|}{ Family history } \\
\hline No & $18(53 \%)$ & $24(52 \%)$ \\
\hline Yes & $11(32 \%)$ & $08(17 \%)$ \\
\hline Uncertain & $05(15 \%)$ & $14(30 \%)$ \\
\hline Duration of follow-up (in months) mean \pm SD (range) & $11.01 \pm 6.19(3-25)$ & $11 \pm 6.31(3-27)$ \\
\hline \multicolumn{3}{|l|}{ Neurological Examination } \\
\hline Normal & $34(100 \%)$ & \\
\hline $\begin{array}{l}\text { Neurological sign (hemiparesis, lower facial } \\
\text { weakness, Babinski sign, sensory deficit, } \\
\text { hemianopia, and dysarthria)* }\end{array}$ & - & $25(59 \%)$ \\
\hline $\begin{array}{l}\text { Other discrete symptoms- } \\
\text { (mild asymmetric deep tendon reflex, tremor) }\end{array}$ & & $19(41 \%)$ \\
\hline Hachinski ischemic score mean $\pm \mathrm{SD}$ (range) & $2.90 \pm 0.6(1-4)$ & $9.13 \pm 2.61(5-19)$ \\
\hline \multicolumn{3}{|l|}{ CT scans: } \\
\hline Normal & $19(56 \%)$ & - \\
\hline Mild diffuse atrophy AND/OR $\uparrow$ ventricles & $15(44 \%)$ & - \\
\hline Atrophy + leukoaraiosis & - & $12(26 \%)$ \\
\hline Focal abnormality & - & $34(74 \%)$ \\
\hline
\end{tabular}

DM: Diabetes Mellitus; *NINDS-AIREN suggested symptoms.

Educational level was an independent predictor of progression in both $\mathrm{AD}$ and $\mathrm{VaD}$ : the higher the education, the worse the severity of dementia. Other longitudinal studies have shown that highly educated patients and those who have had greater participation in prediagnostic intellectual activities have faster cognitive decline than less educated patients; however, these groups have similar mortality rates $[9,10]$. Surrogates of higher cognitive reserve, such as higher educational level, higher occupational attainment, and higher premorbid reading activity, have been associated with faster cognitive decline in patients with dementia [29, 30]. Those individuals with greater cognitive reserve may tolerate a greater burden of neuropathologic conditions in $\mathrm{AD}$ before clinical disease expression; relatively advanced neuropathologic disease by the time of diagnosis may result in faster disease progression [9, 29-31]. Cognitive reserve may also have played a role in bearing the burden of a cerebrovascular mechanism disrupting cognitive processing until the point at which the patient manifests cognitive impairment. Higher education was associated with faster decline even in a sample presenting a relatively low level of education. In this case, a small difference in educational level is sufficient to contribute to the progression of dementia. Because developing and developed countries present distinct educational ranges, one could argue that this difference could reflect a generally faster severity of decline in developed countries.

Progression of disease severity in $\mathrm{AD}$ and $\mathrm{VaD}$ was similar during the period of observation without control for vascular risk factors. At the 12-month follow-up, about $5 \%$ of the participants had deteriorated; at 15 months, about $9 \%$; at 20 months, 18\%; at 23 months, $28 \%$; at 24 months, $42 \%$ of the patients had already deteriorated. On the other hand, when controlled for vascular risk factors, the data showed that at 13 months of observation $10 \%$ of $\mathrm{AD}$ patients had deteriorated; at 15 months, $17 \%$; at 12 months, $32 \%$; at 23 months $37 \%$; at 24 months, $84 \%$ of these patients had declined. Among the $\mathrm{VaD}$ patients, only $2 \%$ of the patients declined before month 23 , and at 24 months, about $10 \%$ had already deteriorated. The slower progression of $\mathrm{VaD}$ was observed with statistical control for hypertension and educational attainment. Despite the borderline significance of the $\mathrm{AD}$ and $\mathrm{VaD}$ difference, this result deserves attention. Contrary to our previous hypothesis, we found a slower decline 
Table 2: Predictive factors in Cox Proportionate Hazards Models, including diagnosis of dementia, age, educational level, sex, family history of dementia, and CT scan findings, for the progression of dementia (worsening of severity according to CDR scale).

\begin{tabular}{|c|c|c|c|c|}
\hline Variable & Hazards ratio & CI 95\% lower-upper & $P$-value & $r$ \\
\hline Diagnosis of dementia & 0.949 & $0.30-3.05$ & .939 & -0.053 \\
\hline Age & 1.049 & $0.96-1.15$ & .318 & 0.048 \\
\hline Sex & 0.433 & $11-1.70$ & .230 & -0.838 \\
\hline Educational level & 1.185 & $1.02-1.37$ & .024 & 0.170 \\
\hline Family history of dementia & & & .785 & \\
\hline Present & 0.983 & $0.24-4.08$ & .982 & -0.017 \\
\hline Unknown & 0.559 & $0.11-2.89$ & .487 & -0.581 \\
\hline CT findings & & & .881 & \\
\hline Mild diffuse atrophy AND/OR $\uparrow$ ventricles & 15831.99 & $0.00-6.2 E^{+096}$ & .929 & 9.670 \\
\hline Atrophy + leukoaraiosis & 34834.69 & $0.00-1.4 E^{+097}$ & .923 & 10.458 \\
\hline Focal abnormality & 16949.11 & $0.00-6.6 E^{+096}$ & .929 & 9.738 \\
\hline
\end{tabular}

Diagnosis of dementia: $0=\mathrm{VaD} ; 1=\mathrm{AD}$.

Table 3: Predictive factors in Cox Proportionate Hazards Models, including diagnosis of dementia, age, educational level, sex, family history of dementia, CT scan findings, and vascular risk factors, for the progression of dementia (worsening of severity according to CDR scale).

\begin{tabular}{|c|c|c|c|c|}
\hline Variable & Hazards ratio & CI 95\% lower-upper & $P$-value & $r$ \\
\hline Diagnosis of dementia & 18.627 & $0.94-370.77$ & .055 & 2.925 \\
\hline Age & 1.060 & $96-1.17$ & .254 & 0.058 \\
\hline Sex & 0.510 & $0.13-1.96$ & .327 & -0.673 \\
\hline Educational level & 1.323 & $1.10-1.59$ & .002 & 0.280 \\
\hline Vascular risk factors & & & .329 & \\
\hline Hypertension & 38.32 & $1.37-1070.3$ & .032 & 3.646 \\
\hline Diabetes mellitus & 0.000 & $0.00-2.3 E^{+101}$ & .992 & -9.928 \\
\hline Hypertension + diabetes mellitus & 28.30 & $0.74-1082.7$ & .072 & 3.343 \\
\hline Family history of dementia & & & .339 & \\
\hline Present & 0.473 & $0.09-2.62$ & .392 & -0.748 \\
\hline Unknown & 0.305 & $0.05-1.81$ & .191 & -1.187 \\
\hline CT findings & & & .985 & \\
\hline Mild diffuse atrophy AND/OR $\uparrow$ ventricles & 547201.7 & $0.00-8.5 E^{+111}$ & .919 & 13.213 \\
\hline Atrophy + leukoaraiosis & 728853.1 & $0.00-1.1 E^{+117}$ & .918 & 13.499 \\
\hline Focal abnormality & 392780.9 & $0.00-6.1 E^{+116}$ & .921 & 12.881 \\
\hline
\end{tabular}

Diagnosis of dementia: $0=\mathrm{VaD} ; 1=\mathrm{AD}$.

for $\mathrm{VaD}$ patients. We can hypothesize that hypertension, a stronger risk factor for the progression of dementia [19, 20, $32-34]$, masked the association of diagnosis (AD or VaD) with the progression of dementia. The adjusted model for hypertension revealed the faster decline of the $\mathrm{AD}$ patients. This finding is not surprising because hypertension is the main risk factor for stroke, and some types of stroke are more common causes of $\mathrm{VaD}$. Therefore, the effect of hypertension is more important for the progression of $\mathrm{VaD}$ than for $\mathrm{AD}$, and the mathematical control with the Cox regression analysis showed this difference. Hypertension is the major risk factor for $\mathrm{VaD}$ [34] and can be considered a prognostic factor for the progression of this disease.

Studies have previously evaluated prognostic factors for $\mathrm{AD}[6-11,21-24]$ and for vascular dementia [13-16]. However, studies comparing the risk or prognostic factors in $\mathrm{AD}$ and $\mathrm{VaD}$ are scarce.
Hypertension is a direct risk factor for $\operatorname{VaD}[16,18,19$, $34,35]$, and other studies have suggested that hypertension also impacts the prevalence of $\mathrm{AD}[20,32]$; however, the effect of vascular risk factors on disease progression after established dementia remains to be elucidated. Our study highlights the significance of vascular risk factors, especially hypertension, on the progression of the severity of dementia, and the consequence of this finding is important. High blood pressure in midlife is associated with a higher incidence of both $\mathrm{AD}$ and $\mathrm{VaD}$ in later life in longitudinal studies [20, 32, $36,37]$. Chronically high blood pressure is associated with vessel wall thickening and narrowing of the vessel lumens in microvessels and large cerebral arteries. Rupture of the atheromatous plaques of larger cerebral arteries can cause complete occlusion of these arteries and infarction of the adjacent cerebral areas [38]. The ischemia and infarction of areas of the brain involved in memory and function 
increase the risk of vascular dementia [35]. Furthermore, hypoxia-induced factors derived from ischemia may potentiate amyloidogenic mechanisms and the development of $\mathrm{AD}$ [39]. We hypothesize that hypertension affects the progression of dementia by the same mechanisms involved in the pathogenesis and clinical manifestation of disease. High blood pressure is a main risk factor for white-matter lesions, which could promote faster progression of both $\mathrm{VaD}$ and $\mathrm{AD}$. The atherosclerotic burden in the brain related to hypertension could also promote more rapid decline. Additionally, atherosclerosis and inadequate treatment of hypertension may induce cerebral hypoperfusion, ischemia, and hypoxia that could hasten cognitive decline. The treatment of the modifiable risk factors, such as hypertension, diabetes mellitus, hypercholesterolemia, and heart disease, is a strategy for the reduction of the risk of dementia [4042]. Although we did not evaluate this issue, we may expect that the treatment of these vascular risks factors has a similar effect on slowing the progression of cognitive decline in dementia.

The strengths of the present study were the well-defined and well-evaluated vascular risk factors at entry to the study, the statistical model of prediction, the $\mathrm{AD}$ and $\mathrm{VaD}$ grouping sample, and the relevance of the main findings for developing countries. The definition and evaluation of vascular risk factors were designed to be comprehensive and reliable. We did not include the previous history or incident stroke as vascular risk factor because only $\mathrm{VaD}$ patients had previous history of stroke at baseline and incident stroke was not observed during the follow-up. The statistical model of prediction, adjustment, and control for variables, as well as the graphic illustrations, demonstrated very well what could have occur if the vascular risk factors, mainly hypertension, were actually controlled.

One limitation of the present study was that there was no distinction of $\mathrm{VaD}$ subtypes. Concept and definition of $\mathrm{VaD}$ are heterogeneous and the term $\mathrm{VaD}$ encompasses many different subtypes. These differences certainly have an impact on the clinical course of the disease. The various forms of $\mathrm{VaD}$ present different clinical, neuroimaging, and pathological features which may affect the clinical course in diverse ways. We used the NINDS/AIREN criteria to define vascular dementia, which is the most frequently used and the most restrictive. We also used the Hachinski Ischemic Score (HIS) to verify that an ischemic process was associated with $\mathrm{VaD}$ and to exclude ischemia in $\mathrm{AD}$. Then, our results cannot be generalized to all definitions of $\mathrm{VaD}$.

\section{Conclusion}

This longitudinal study showed a similar severity of decline in both $\mathrm{AD}$ and $\mathrm{VaD}$ during two years. The impact of hypertension and education on the progression of dementia was also demonstrated. Vascular risk factors interacted with the diagnosis of $\mathrm{VaD}$. Education was a strong predictor of decline. Finally, the importance of the present findings is reinforced by the information that disability has a greater absolute (and relative) impact on healthy-life expectancy at birth in poorer countries [43], and prevalence and rates of increase of dementia are higher in developing than in developed regions $[1,44]$. Health public strategies to prevent and control treatable conditions such as hypertension may have an important impact on the burden of dementia in developing countries.

\section{Competing Interests}

The author(s) declare that they have no competing interests.

\section{Author's Contributions}

M. L. Chaves designed the study, was responsible for the statistical design of the study, supervised the data collection, and wrote the paper. A. L. Camozzato supervised the data collection, was responsible for carrying out the statistical analysis, and wrote the paper; C. Köhler collected the data and assisted with statistical analysis; J. Kaye assisted with writing the paper.

\section{Acknowledgment}

This study was supported by Grants from CNPq (350027/ 1995-1 and 306458/2004-7).

\section{References}

[1] C. P. Ferri, M. Prince, C. Brayne, et al., "Global prevalence of dementia: a Delphi consensus study," The Lancet, vol. 366, no. 9503, pp. 2112-2117, 2005.

[2] A. Ott, M. M. B. Breteler, F. van Harskamp, et al., "Prevalence of Alzheimer's disease and vascular dementia: association with education. The Rotterdam study," British Medical Journal, vol. 310, no. 6985, pp. 970-973, 1995.

[3] I. Skoog, L. Nilsson, B. Palmertz, L.-A. Andreasson, and A. Svanborg, "A population-based study of dementia in 85-yearolds," The New England Journal of Medicine, vol. 328, no. 3, pp. 153-158, 1993.

[4] A. L. Fitzpatrick, L. H. Kuller, O. L. Lopez, C. H. Kawas, and W. Jagust, "Survival following dementia onset: Alzheimer's disease and vascular dementia," Journal of the Neurological Sciences, vol. 229-230, pp. 43-49, 2005.

[5] G.-H. Suh, Y.-S. Ju, B. K. Yeon, and A. Shah, "A longitudinal study of Alzheimer's disease: rates of cognitive and functional decline," International Journal of Geriatric Psychiatry, vol. 19, no. 9, pp. 817-824, 2004.

[6] G. R. J. Swanwick, R. F. Coen, D. Coakley, and B. A. Lawlor, "Assessment of progression and prognosis in possible and probable Alzheimer's disease," International Journal of Geriatric Psychiatry, vol. 13, no. 5, pp. 331-335, 1998.

[7] R. G. Stern, R. C. Mohs, M. Davidson, et al., "A longitudinal study of Alzheimer's disease: measurement, rate, and predictors of cognitive deterioration," American Journal of Psychiatry, vol. 151, no. 3, pp. 390-396, 1994.

[8] D. X. Rasmusson, K. A. Carson, R. Brookmeyer, C. Kawas, and J. Brandt, "Predicting rate of cognitive decline in probable Alzheimer's disease," Brain and Cognition, vol. 31, no. 2, pp. 133-147, 1996.

[9] E. P. Helzner, N. Scarmeas, S. Cosentino, F. Portet, and Y. Stern, "Leisure activity and cognitive decline in incident Alzheimer disease," Archives of Neurology, vol. 64, no. 12, pp. 1749-1754, 2007. 
[10] A. Bruandet, F. Richard, S. Bombois, et al., "Cognitive decline and survival in Alzheimer's disease according to education level," Dementia and Geriatric Cognitive Disorders, vol. 25, no. 1, pp. 74-80, 2007.

[11] N. Scarmeas, J. Brandt, D. Blacker, et al., "Disruptive behavior as a predictor in Alzheimer disease," Archives of Neurology, vol. 64, no. 12, pp. 1755-1761, 2007.

[12] I. Buccione, R. Perri, G. A. Carlesimo, et al., "Cognitive and behavioural predictors of progression rates in Alzheimer's disease," European Journal of Neurology, vol. 14, no. 4, pp. 440 446, 2007.

[13] A. L. Jefferson, D. Cahn-Weiner, P. Boyle, et al., "Cognitive predictors of functional decline in vascular dementia," International Journal of Geriatric Psychiatry, vol. 21, no. 8, pp. 752754, 2006

[14] C. Reitz, M. J. Bos, A. Hofman, P. J. Koudstaal, and M. M. B. Breteler, "Prestroke cognitive performance, incident stroke, and risk of dementia: the Rotterdam Study," Stroke, vol. 39, no. 1, pp. 36-41, 2008.

[15] D. S. Knopman, W. A. Rocca, R. H. Cha, S. D. Edland, and E. Kokmen, "Survival study of vascular dementia in Rochester, Minnesota," Archives of Neurology, vol. 60, no. 1, pp. 85-90, 2003.

[16] G. C. Roman, "Vascular dementia prevention: a risk factor analysis," Cerebrovascular Diseases, vol. 20, supplement 2, pp. 91-100, 2005.

[17] G. W. Ross, H. Petrovitch, L. R. White, et al., "Characterization of risk factors for vascular dementia: the Honolulu- Asia aging study," Neurology, vol. 53, no. 2, pp. 337-343, 1999.

[18] R. Hebert, J. Lindsay, R. Verreault, K. Rockwood, G. Hill, and M.-F. Dubois, "Vascular dementia: incidence and risk factors in the canadian study of health and aging," Stroke, vol. 31, no. 7, pp. 1487-1493, 2000.

[19] K. M. Hayden, P. P. Zandi, C. G. Lyketsos, et al., "Vascular risk factors for incident Alzheimer disease and vascular dementia: the Cache County Study," Alzheimer Disease and Associated Disorders, vol. 20, no. 2, pp. 93-100, 2006.

[20] M. Kivipelto, E.-L. Helkala, M. P. Laakso, et al., "Midlife vascular risk factors and Alzheimer's disease in later life: longitudinal, population based study," British Medical Journal, vol. 322, no. 7300, pp. 1447-1451, 2001.

[21] C. Regan, C. Katona, Z. Walker, J. Hooper, J. Donovan, and G. Livingston, "Relationship of vascular risk to the progression of Alzheimer disease," Neurology, vol. 67, no. 8, pp. 1357-1362, 2006.

[22] M. Silvestrini, P. Pasqualetti, R. Baruffaldi, et al., "Cerebrovascular reactivity and cognitive decline in patients with Alzheimer disease," Stroke, vol. 37, no. 4, pp. 1010-1015, 2006.

[23] M. M. Mielke, P. B. Rosenberg, J. Tschanz, et al., "Vascular factors predict rate of progression in Alzheimer disease," Neurology, vol. 69, no. 19, pp. 1850-1858, 2007.

[24] D. Bhargava, M. F. Weiner, L. S. Hynan, R. Diaz-Arrastia, and A. M. Lipton, "Vascular disease and risk factors, rate of progression, and survival in Alzheimer's disease," Journal of Geriatric Psychiatry and Neurology, vol. 19, no. 2, pp. 78-82, 2006.

[25] G. C. Roman, T. K. Tatemichi, T. Erkinjuntti, et al., "Vascular dementia: diagnostic criteria for research studies: report of the NINDS-AIREN International Workshop," Neurology, vol. 43, no. 2, pp. 250-260, 1993.

[26] V. C. Hachinski, L. D. Iliff, and E. Zilhka, "Cerebral blood flow in dementia," Archives of Neurology, vol. 32, no. 9, pp. 632-637, 1975.
[27] M. L. F. Chaves, A. L. Camozzato, C. Godinho, et al., "Validity of the clinical dementia rating scale for the detection and staging of dementia in Brazilian patients," Alzheimer Disease and Associated Disorders, vol. 21, no. 3, pp. 210-217, 2007.

[28] J. C. Morris, "The Clinical Dementia Rating (CDR): current version and scoring rules," Neurology, vol. 43, no. 11, pp. 24122414, 1993.

[29] Y. Stern, S. Albert, M.-X. Tang, and W.-Y. Tsai, "Rate of memory decline in $\mathrm{AD}$ is related to education and occupation: cognitive reserve?" Neurology, vol. 53, no. 9, pp. 1942-1947, 1999.

[30] R. S. Wilson, D. A. Bennett, D. W. Gilley, L. A. Beckett, L. L. Barnes, and D. A. Evans, "Premorbid reading activity and patterns of cognitive decline in Alzheimer disease," Archives of Neurology, vol. 57, no. 12, pp. 1718-1723, 2000.

[31] R. S. Wilson, Y. Li, N. T. Aggarwal, et al., "Education and the course of cognitive decline in Alzheimer disease," Neurology, vol. 63, no. 7, pp. 1198-1202, 2004.

[32] L. J. Launer, G. W. Ross, H. Petrovitch, et al., "Midlife blood pressure and dementia: the Honolulu-Asia aging study," Neurobiology of Aging, vol. 21, no. 1, pp. 49-55, 2000.

[33] I. Skoog, B. Lernfelt, S. Landahl, et al., "15-year longitudinal study of blood pressure and dementia," The Lancet, vol. 347, no. 9009, pp. 1141-1145, 1996.

[34] P. Scheinberg, "Dementia due to vascular disease-a multifactorial disorder," Stroke, vol. 19, no. 10, pp. 1291-1299, 1988.

[35] S. P. Kennelly, B. A. Lawlor, and R. A. Kenny, "Blood pressure and the risk for dementia-a double edged sword," Ageing Research Reviews, vol. 8, no. 2, pp. 61-70, 2009.

[36] R. A. Whitmer, S. Sidney, J. Selby, S. C. Johnston, and K. Yaffe, "Midlife cardiovascular risk factors and risk of dementia in late life," Neurology, vol. 64, no. 2, pp. 277-281, 2005.

[37] M. Yamada, F. Kasagi, H. Sasaki, N. Masunari, Y. Mimori, and G. Suzuki, "Association between dementia and midlife risk factors: the radiation effects research foundation Adult Health Study," Journal of the American Geriatrics Society, vol. 51, no. 3, pp. 410-414, 2003.

[38] J. D. Swales, "Pharmacological treatment of hypertension," The Lancet, vol. 344, no. 8919, pp. 380-385, 1994.

[39] X. Zhang, K. Zhou, R. Wang, et al., "Hypoxia-inducible factor $1 \alpha$ (HIF- $1 \alpha)$-mediated hypoxia increases BACE1 expression and $\beta$-amyloid generation," The Journal of Biological Chemistry, vol. 282, no. 15, pp. 10873-10880, 2007.

[40] B. A. In't Veld, A. Ruitenberg, A. Hofman, B. H. Stricker, and M. M. B. Breteler, "Antihypertensive drugs and incidence of dementia: the Rotterdam Study," Neurobiology of Aging, vol. 22, no. 3, pp. 407-412, 2001.

[41] F. Forette, M.-L. Seux, J. A. Staessen, et al., “The prevention of dementia with antihypertensive treatment: new evidence from the systolic hypertension in Europe (Syst-Eur) study," Archives of Internal Medicine, vol. 162, no. 18, pp. 2046-2052, 2002.

[42] C. Patterson, J. W. Feightner, A. Garcia, G.-Y. R. Hsiung, C. MacKnight, and A. D. Sadovnick, "Diagnosis and treatment of dementia: 1. Risk assessment and primary prevention of Alzheimer disease," Canadian Medical Association Journal, vol. 178 , no. 5, pp. 548-556, 2008.

[43] C. D. Mathers, R. Sadana, J. A. Salomon, C. J. L. Murray, and A. D. Lopez, "Healthy life expectancy in 191 countries, 1999," The Lancet, vol. 357, no. 9269, pp. 1685-1691, 2001.

[44] A. Wimo, B. Winblad, H. Aguero-Torres, and E. von Strauss, "The magnitude of dementia occurrence in the world," Alzheimer Disease and Associated Disorders, vol. 17, no. 2, pp. 63-67, 2003. 


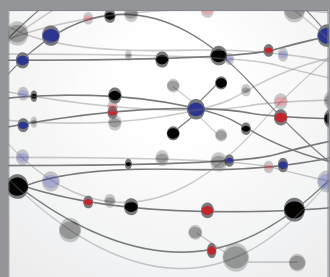

The Scientific World Journal
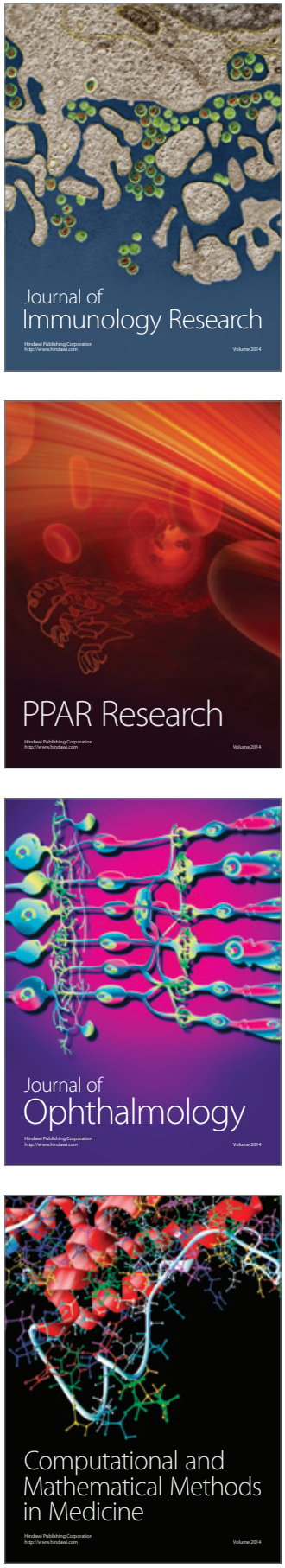

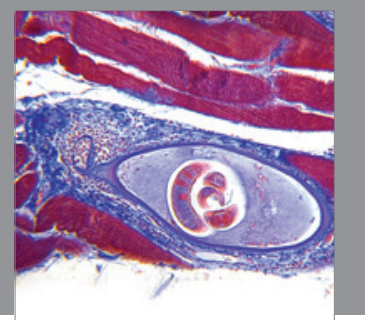

Gastroenterology

Research and Practice
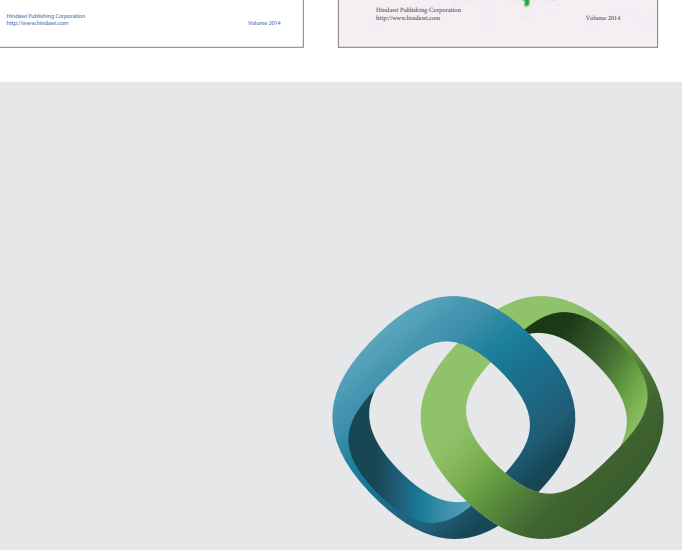

\section{Hindawi}

Submit your manuscripts at

http://www.hindawi.com
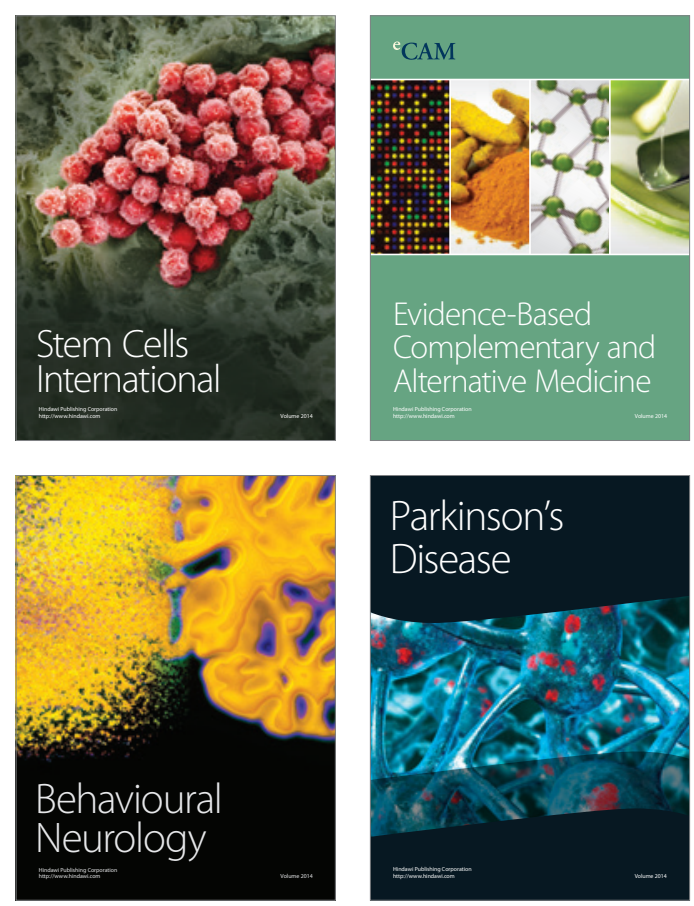

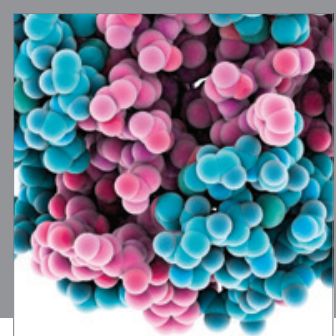

Journal of
Diabetes Research

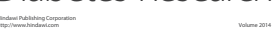

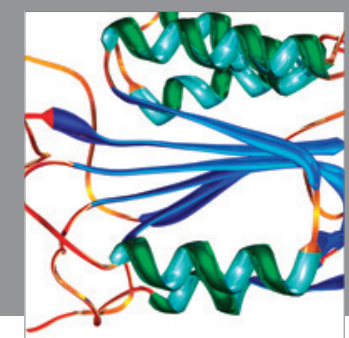

Disease Markers
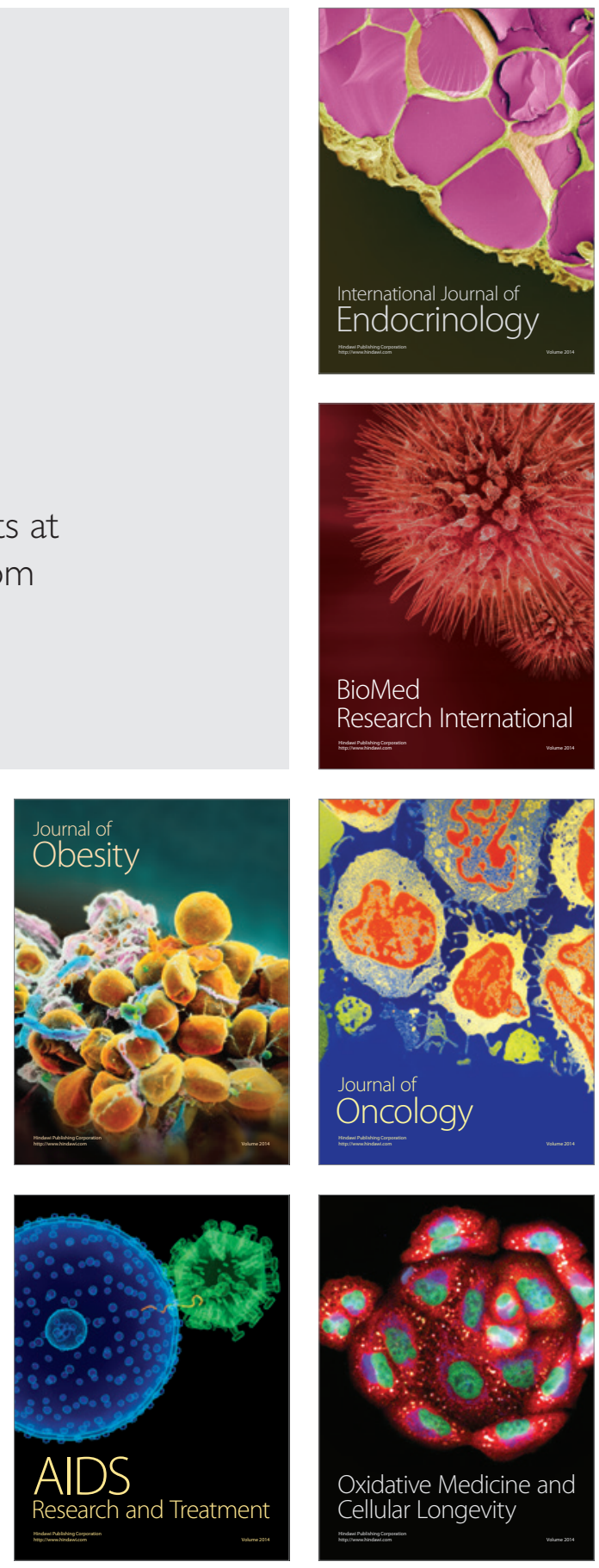